This is the author's manuscript for publication. The publisher-formatted version may be available through the publisher's web site or your institution's library.

\title{
Management of content development and subject engagement through an arts matrix model: a case study
}

Casey D. Hoeve, Ellen R. Urton, and Thomas W. Bell

\section{How to cite this manuscript}

If you make reference to this version of the manuscript, use the following information:

Hoeve, C. D., Urton, E. R., \& Bell, T. W. (2014). Management of Content Development and Subject Engagement through an Arts Matrix Model: A Case Study.

\section{Published Version Information}

\section{Citation:}

Hoeve, C. D., Urton, E. R., \& Bell, T. W. (2014). Management of Content Development and Subject Engagement through an Arts Matrix Model: A Case Study. In A. Woodsworth, W. D. Penniman (ed.), Management and Leadership Innovations (Advances in Librarianship, Volume 38) Emerald Group Publishing Limited, pp.177 210.

Digital Object Identifier (DOI): 10.1108/S0065-2830_2014_0000038001

Publisher's Link: http://www.emeraldinsight.com/doi/abs/10.1108/S0065283020140000038001 


\title{
Management of Content Development and Subject Engagement through an Arts Matrix Model: A Case Study
}

\author{
Casey D. Hoeve, Ellen R. Urton, and Thomas W. Bell
}

Libraries, Kansas State University, Manhattan, KS, USA

\begin{abstract}
From 2007 - 2009, Kansas State University Libraries (K-State Libraries) committed to strategically assess and redevelop their organizational structure. The Libraries' Strategic Plan and position redistributions commenced in 2007 and 2009 respectively, with adjustments in 2010 to accommodate the university's “K-State 2025" Strategic Plan. Together, these plans changed the roles of former subject librarians, dividing and transferring responsibilities for outreach, reference, instruction, and collection development. Among the more significant changes was the creation of departments devoted to patron groups, rather than specific academic disciplines. Illustrating how the reorganization changed the roles of traditional library services, this chapter will outline the responsibilities of three librarian positions: Undergraduate and Community Services, Faculty and Graduate Services, and Content (collection) Development. The librarians are also founding members of the K-State Libraries Arts Matrix, an ad hoc team operating within the new organization to enhance communication and expand subject expertise in the visual and performing arts. These transitions presented both opportunities for engagement and specialization, and challenges to communication and subject identity. These issues are addressed, including solutions offered by the matrix model. Although this study is limited by the neoteric existence of this model, and lack of precedents for comparison, K-State Libraries' example may offer a viable model for institutions adapting to fiscal realities. Additionally, matrices may supplement the traditional subject librarian model for those seeking to enhance engagement and collaboration. This chapter offers further insight into a strategic planning process, as well as a transparent, inclusive strategy for librarians adjusting to organizational change.
\end{abstract}

Keywords: collection development, matrix, reorganization, engagement, team-based.

Classification: Case study 
Management of Content Development and Subject Engagement through an Arts Matrix Model:

$$
\text { A Case Study }
$$

Kansas State University (K-State) is a public, 4-year doctoral granting institution, classified as a Research University by the Carnegie Classification of Institutions of Higher Education (Carnegie Foundation, 2010). Founded in 1863, K-State was one of the first land-grant institutions in the United States. Presently, K-State is an aggregate of 3 campuses, with its main campus located in Manhattan, and branch locations in Salina (College of Aviation and Technology) and Olathe (located approximately one hour and two hours from the main campus, respectively).

Additionally, the K-State Office of Research and Extension serves all 105 counties in Kansas, providing community outreach programs to improve the lives of rural and urban citizens (Kansas State University, Research and Extension, 2013c). K-State Libraries collectively support the philosophy and mission of a land-grant institution. It is within this environment that the K-State Libraries Arts Matrix operates, advocating for the visual and performing arts at a university that excels in and emphasizes traditional land grant subjects including agriculture, engineering, and the sciences.

The initial steps of the Libraries' strategic planning and reorganization began in 2007, in response to technological advances and current trends in library service models, and to align with the strategic goals of the university. The authors present this narrative as a means to describe a lesser known team-based model that is not currently well documented in the academic literature. The choices made by administration are detailed, as well as the strategies implemented to adequately represent all library employees in the decision making process. Additionally, a comparison of the traditional configuration prior to the reorganization establishes the scope of the changes and contextualizes the impact of the new structure on the roles of the librarians discussed in this case study. Documentation of the K-State Libraries' process offers a method of evaluating the matrix model that will allow other institutions insight into the impact of this unique organizational structure.

The experience of the founding members of the Arts Matrix in this transition provides an example of how one of the K-State Libraries' matrices functions within the new organizational structure. Through this example, this study presents issues common to all disciplines as they adapt to fiscal realities and technological automations, while striving to make library resources and services more desiderable to the academic enterprise in their unique communities. 


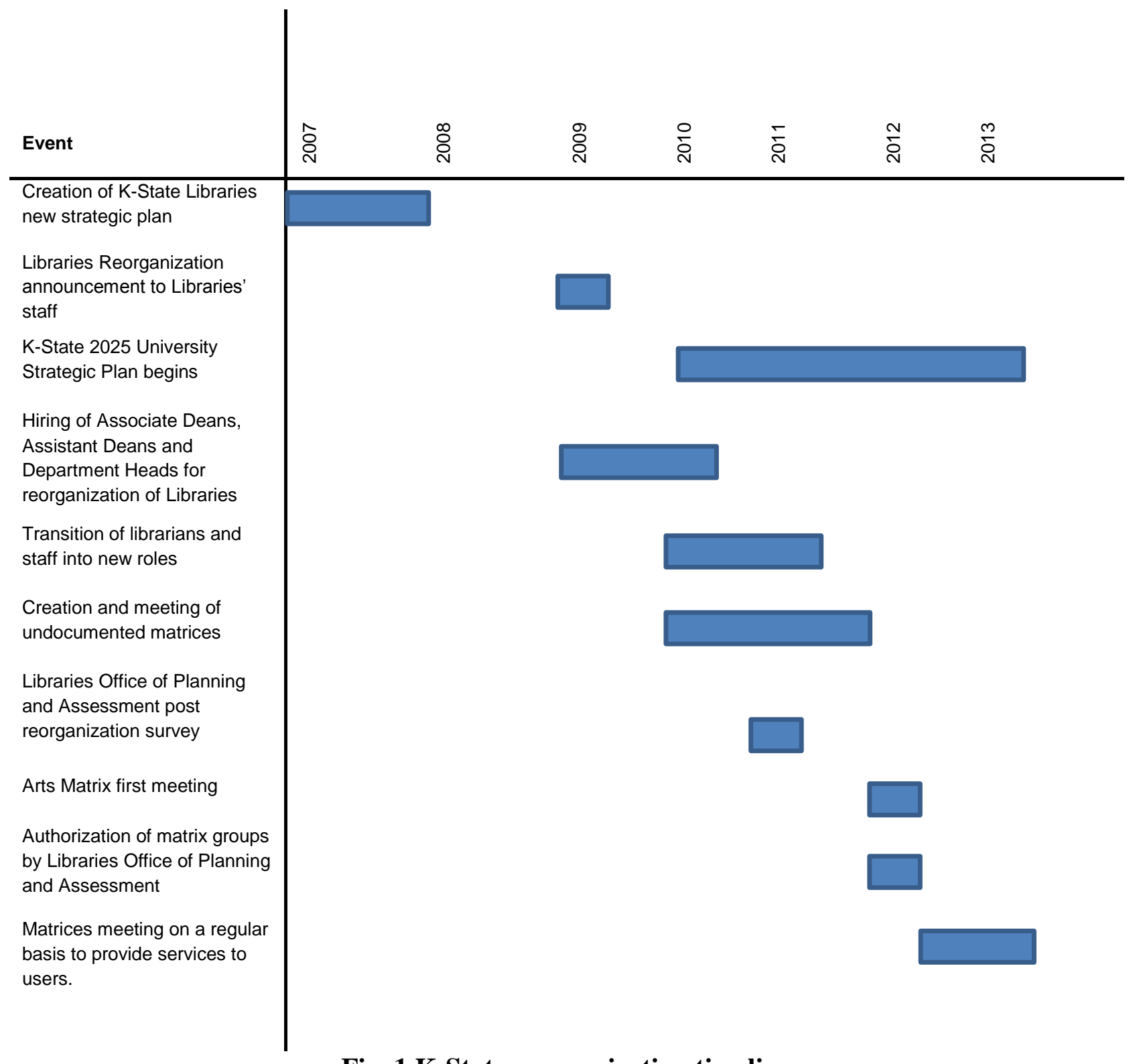

Fig. 1 K-State reorganization timeline

\section{Strategic Planning}

\section{Libraries Strategic Plan}

This overview of the K-State Libraries' organization and strategic planning process highlights the rationale behind the decision to reorganize the library system, beginning in 2007 . The Libraries' strategic plan established the philosophical framework that underlies the matrix model and produced significant impacts upon content development and subject engagement. 
The preceding plan tentatively expired in 2006, requiring modifications to reflect current trends in academic service models. Subsequently, adjustments were also requisite to meeting forthcoming challenges in library services, including prioritized areas of information literacy, collection management, and e-resource proficiency. A strategic planning committee facilitated the development of objectives and the finalized plan was expected to be implemented in incremental stages from 2007 - 2012, after which, it would be subject to review and alteration.

A total of thirteen library employees were selected to serve on the ad hoc strategic planning committee; the committee's first act was the generation of a report, profiling the status of the Libraries. It was determined that the previous plan was unable to adapt to forthcoming challenges of digital information, specifically prospective advancement in the next five years. Committee representatives met with department members and university stakeholders, finalizing “A living strategic plan: K-State Libraries, 2007-2012," which outlined five specific goals for the Libraries:

Goal 1. "Our patrons will find collections tailored and managed to meet their changing needs and advance the priorities of the university (K-State Libraries, 2006, p. 4).”

Goal 2. "Our users will have seamless, user-driven access to reliable information, scholarship, and services when and where needed and have opportunities to learn how to effectively use and apply these resources (K-State Libraries, 2006, p. 4).”

Goals 1 and 2 established the means to apply greater levels of metric analysis to decision making processes, creating an academically sound collection which encouraged use through the provision of popular and sustainable formats. As evidenced by changing trends in library usage and materials purchasing, it was generally observed that acquisitions of electronic based content had been steadily increasing, corresponding with the availability of e-resources offered by information vendors. The sheer availability and duplication of materials in print and digital formats, as well as physical media and streaming content, yielded an opportunity to better assess what patrons were using, specifically addressing format preference.

In addition to improving acquisition methodology, the Libraries recognized the need for advanced instructional services to complement modern resources in the collection. K-State Libraries prided themselves on excellent customer service; however, it was clear that new technologies created a literacy gap in faculty and student research capabilities. Goal 2 therefore dictated a shift in the traditional service model, allowing librarians to become more accessible, and "take the library to the user" (K-State Libraries, 2006, p. 5). Addressing the evolving roles of contemporary academic librarians as teachers and partners in crafting educational experiences enabled additional innovative practices for collaborating and communicating with patrons. 
Information literacy sessions were tailored to fit new electronic interfaces, providing students and faculty with skill sets for lifelong learning and technological adaptations. Traditional elements of information literacy were retained in the instructional model, to help users develop into critical examiners of authoritative scholarship.

Goal 3. "The Libraries will increasingly support the creation, discovery, sharing, and preservation of the unique digital academic and institutional knowledge assets produced at our university (K-State Libraries, 2006, p. 6).”

The third goal of the strategic plan implemented a scholarly communications and open access publishing framework within the Libraries. The acquisition and conversion of materials was to be completed by the Libraries, with incentives to subsidize faculty open-access publishing. The creation of New Prairie Press in 2007, the open access publisher of Kansas State University, provided free support and hosting of journals started by faculty, scholarly organizations, or students (New Prairie Press, 2013). The third goal also supported the digitization of additional materials as recommended by Special Collections \& University Archives employees, to best guide the collection of historical materials representing the State of Kansas, and Kansas State University (K-State Libraries, 2006, p. 6). Educational outreach was to be combined with this program, to provide relevant information about the fair use of publications, open-access licensing models, and the attribution of metadata to digital content. The initial criteria outlined acquisition methods and format preferences, thus defining a process for preserving, storing, and managing university resources in the future.

Goal 4. "Our users will find innovative and welcoming learning spaces, both physical and virtual, that stimulates learning, continually respond to user needs, and enrich the library experience (K-State Libraries, 2006, p. 8).”

The changing functions of library space, patron demands, and again, the expanding roles of librarians helped to formulate the ideas stated in Goal 4. The Libraries wished to remain progressive in comparison with peer institutions, offering popular services representative of modern educational needs. Many of the service trends involved converting materials storage areas into study space, and expanding library assistance beyond the reference desk, as well as beyond physical spaces entirely. The new strategic plan envisioned more support for physical and virtual environments, including innovative online learning objects (e.g. LibGuides, online resource tutorials, virtual tours, etc.), online reference help, 24/7 library access, and the provision of amenities to support a communal atmosphere. It was also anticipated that the library would host several cultural programs and speakers throughout the year, to engage the campus community, and function as a focal point for collaborative university learning (K-State Libraries, 2006, p. 8). 
Goal 5. "Our internal capacity will expand so we can deliver 21 st century library and information services aligned with the University's missions and academic priorities (K-State Libraries, 2006, p. 9)."

This final goal of the strategic plan addressed the internal capacity of the Libraries, and the need for flexibility to respond to transitions in the information environment. The successful completion of Goals 1-4 were contingent upon the Libraries' ability to empower staff, and allow them the latitude to co-create new roles and to acclimate to new responsibilities. The previous strategic plan was dually explicit in its intention, recognizing that objectives should coalesce with campus culture and university strategic planning. To enhance services for users, positions were to be evaluated to improve core work processes, thus utilizing a project plan to refine roles for more efficient service models. Appropriate staffing was deemed critical for maintaining service levels, and it was additionally recognized that staff size should increase as needed to fill vacant or underserved areas of the library (K-State Libraries, 2006).

As the planning phase continued, the Libraries made additional modifications to the strategic plan in 2009, and prioritized the following valued outcomes:

- Move from a collection centered to a user centered organization

- $\quad$ Recognize diverse user needs

- Make data-driven decisions about resources through improved quantitative and qualitative data collection and assessment

- Improve delivery, coordination of information services

- Manage for flexibility and relevance to users

- Clarify reporting relations and balance supervisory workload

- Streamline workflows

- Reallocate human resources to new, emerging needs in order to be more adaptable

- Maximize staff strengths, talents, and interests (K-State Libraries, 2009a, p. 2)

When these objectives were juxtaposed with the library's organizational structure at the time, it was concluded that the structure was too narrow in scope, and yielded fewer opportunities for shared user-centered initiatives. In addition, the Libraries anticipated a $15 \%$ workforce reduction as the result of a university hiring freeze, resignations, and retirements (K-State Libraries, 2009a, p. 2). These cutbacks significantly reduced the Libraries' capacity to put the strategic planning processes into motion, and the decrease in faculty and staff left service gaps in crucial library functions. The Libraries administration made the tough decision to transform the structure, and the job responsibilities of most K-State Libraries faculty members. As the University unveiled its new Strategic Plan in 2010, "K-State 2025," the Libraries were able to better accommodate long term planning and assessment, contributing to the university's goal of becoming a top 50 public research institution by 2025 . 


\section{K-State Libraries Reorganization}

\section{Pre-Reorganization (2008)}

The following discussion offers a snapshot of the K-State Libraries structure before and after the 2009 - 2010 reorganization to contextualize the impact of changes on content development practices and subject engagement. Previous to the organizational change, K-State Libraries utilized the traditional subject-divisional model, similar to the approach popularized in the 1930's by Ralph Ellsworth at the University of Colorado (Kent, Lancour, and Daily, 1978), and Richard Offer at the University of Leeds (Feetham, 2006). At K-State, subject librarians were responsible for performing outreach, instruction, and collection development for specific academic disciplines, usually assigned according to undergraduate or advanced degree expertise. As shown in Figure 2, all library departments were required to report directly to one Associate Dean, responsible for management of subject departments, or the Dean of the Libraries, responsible for financial and facilities services, and human resources.

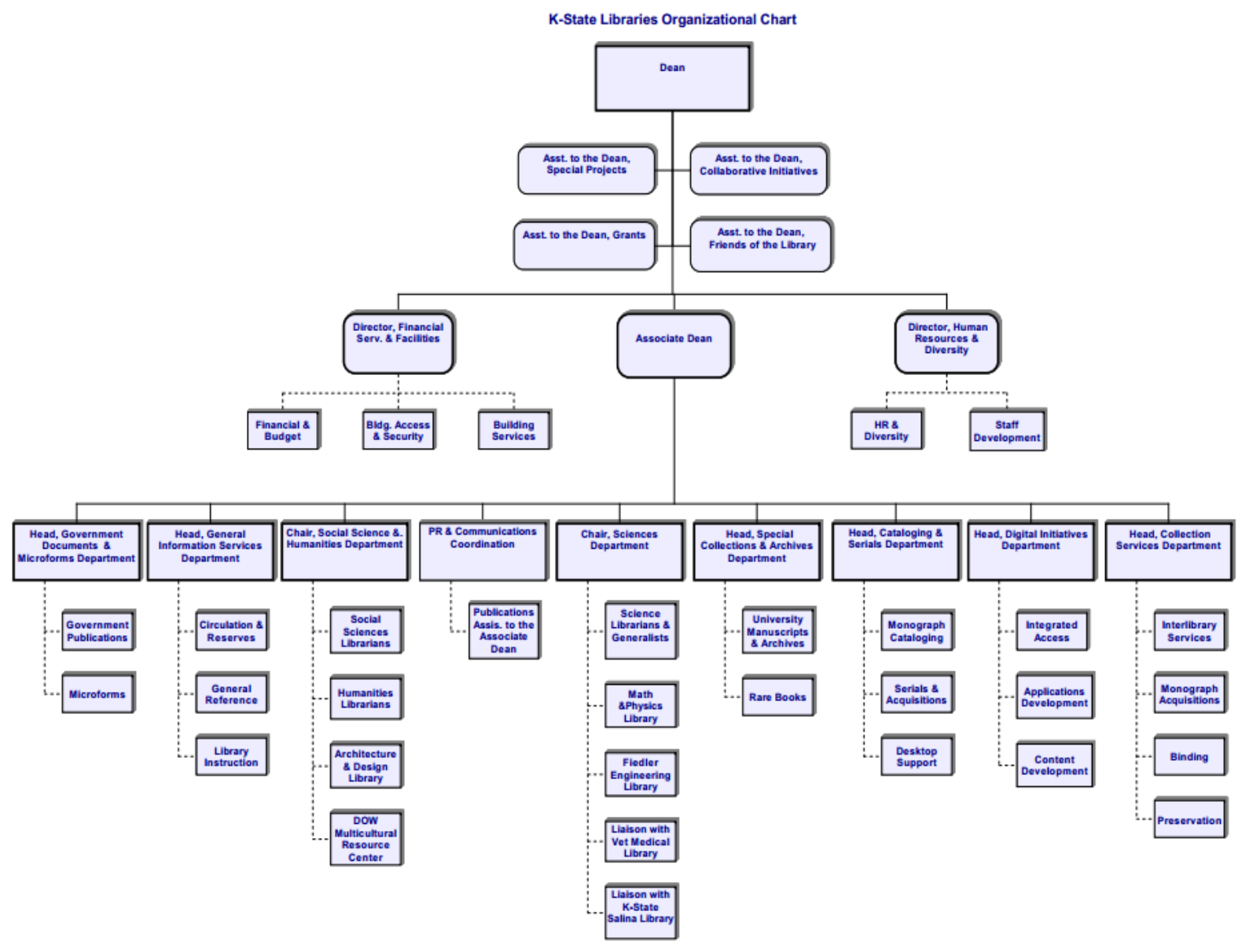

Fig. 2 K-State Libraries organization chart in 2008 (K-State Libraries, 2008b). 
The subject divisions (non-administration) were divided into nine departments:

1. Government Documents \& Microforms

2. General Information Services

3. Social Sciences \& Humanities

4. Public Relations \& Communications Coordination

5. Sciences

6. Special Collections \& Archives

7. Cataloging \& Serials Department

8. Digital Initiatives

9. Collection Services

Divisions operated under relatively autonomous conditions, with a department head supervising librarians and staff under each sub-division. Branch libraries were classified according to subject, including the library at the K-State Salina campus. Subject specialists for the Sciences, Social Sciences, and the Humanities engaged in outreach and instruction at all levels (community, undergraduate, graduate, and faculty), and undertook collection development for monograph resources. For serials and databases, subject specialists consulted with a Collections Council, which vetted requests regarding substantial purchases and academic discipline-based monograph fund allocations. The Collections Council, consisting of library departmental representatives and chairs, the Consortial Liaison, the Associate Dean, and the Acquisitions Librarian acted as the decision-making body. The Council's charge included collections decision making, budget allocation, policy development and use assessment of current resources. Subject librarians coordinated purchasing with the Acquisitions Librarian, who processed requests according to the consensus of the Collections Council, collection priorities, budget, accessibility, and licensing terms.

Under the new reorganization (2009), the appointments of Dean of Libraries and Associate Dean continued, but two Assistant Dean positions were added to head two newly created divisions, along with a Senior Director for Administrative Services/IT and a Director of Human Resources and Diversity. The Associate Dean and Assistant Deans were charged with the task of creating new position descriptions, and determining how job duties would transfer from old divisions into a new structure (Kansas State University, 2010).

\section{Post-Reorganization (2009-2010)}

The reorganization model, unique in its implemented form, was loosely modeled on philosophies exemplified by other libraries and non-library professions. During the planning process, library administrators examined the team-based service model used by the University of Guelph 
Library. Guelph shared circumstances similar to K-State, citing a constrained budget and reduced library staff as motivators for change. It was believed that a team based service model would better leverage expertise across the library (University of Guelph Library, 2013), and increase staff flexibility as new challenges materialized. A comparable team service model was also introduced at the University of Arizona Libraries, confirming that teams could quickly adapt to technological changes in information services (Andrade \& Zaghloul, 2010).

Library administration was adamantly explicit in stating that no librarians or staff members would have to forfeit their job as a result of the reorganization. To diminish fears, support services were offered, aligning each employee's expertise with a potential new appointment. Brief surveys were evaluated by the Associate Dean, Assistant Deans, and department heads to determine interests and skill sets, producing a list of available jobs which most closely matched the responses. Positions were then prioritized according to preference, allowing for comparison against the selections of other colleagues. Much to the delight of library administration, most librarians were able to obtain their first choice. For those who were not able to receive their desired position, extra training was offered to help them make a smoother transition to new responsibilities (K-State Libraries, 2009a, p. 2).

Completion of the organizational chart in 2010 unveiled four new areas, as shown in Figure 3:

- Associate Dean: Communications, Marketing, and the Office of Planning and Assessment (LPA)

- Content Management and Scholarly Communications: Content Management, Scholarly Communications, Acquisitions, Interlibrary Loan, and Resource Linking

- Research Education and Engagement: Undergraduate and Community Services, Faculty and Graduate Services, Circulation, and University Archives and Special Collections

- Administrative and Information Technology Services: Administration, Financial Services, Building Services, and Information Technology

Within each area, multiple departments were furcated, with a department head supervising major projects, librarians, and library staff.

\section{Associate Dean}

The Office of Communications and Marketing coordinates all events at the Libraries, including exhibits, Friends of the K-State Libraries fundraisers, scholarly lectures, and also provides a consistent voice and image for the organization (signs, pamphlets, and promotional items). Web Services frequently partners with marketing to maintain a relevant web presence, and serves as the primary agent for enhancing usability of the library website. Under the Associate Dean, the Libraries' Office of Planning and Assessment (LPA) functions as the steward of the Libraries' strategic plan, organizing responses, themes, and metrics into a feasible procedure. LPA also 
compiles statistics for internal and external reports, and assists with outcome analysis and accreditation (K-State Libraries, 2009b, p. 1).

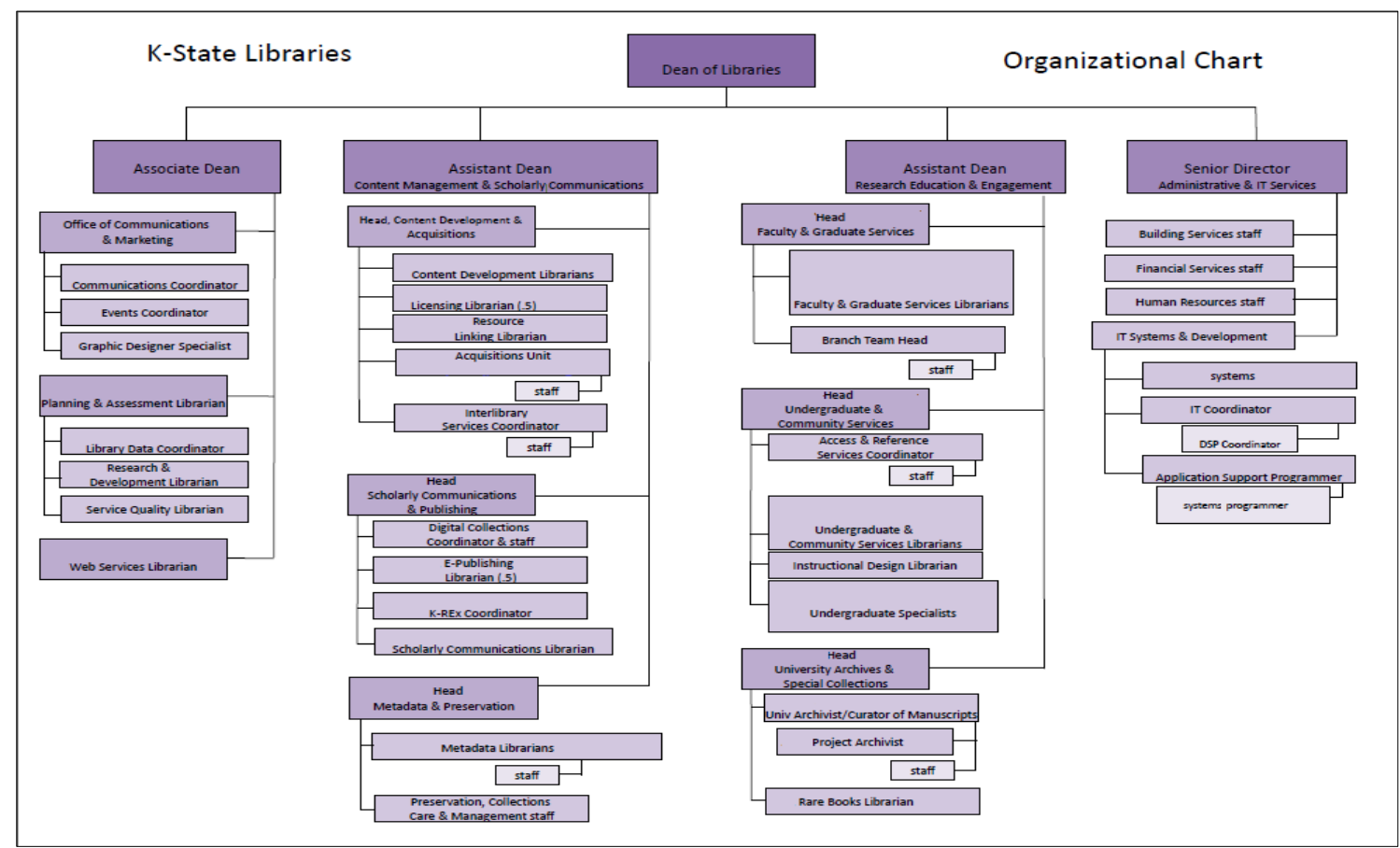

Fig. 3 K-State Libraries reorganization chart (K-State Libraries, 2010a).

\section{Content Management and Scholarly Communications}

The establishment of the division of Content Management \& Scholarly Communications constitutes the most significant change to collection development. This division specializes in the provision of technical services to the Libraries. Duties previously assigned to individual subject librarians and members of the Collections Council were transferred to the purview of Content Development Librarians. Content (collection) Development is primarily responsible for the evaluation and selection of all information resources, as well as undertaking collection management projects such as patron driven acquisitions, collection analysis, and weeding. The Acquisitions unit performs purchasing and budgetary management tasks, including interlibrary loan fulfillment and licensing, while the Resource Sharing Unit maintains link resolvers and web scale discovery systems (K-State Libraries, 2009b, p. 1).

The Cataloging and Metadata department collaborates with Content Development and Acquisitions, to process all information resources purchased by the Libraries. This unit also executes material location transfers, the bulk loading of catalog and metadata records to the server, and assists Scholarly Communications with assigning metadata to digital repository 
objects. The Preservation unit functions alongside Cataloging and Metadata, managing the stacks and a storage annex, and applying appropriate treatments to damaged or at-risk materials (KState Libraries, 2009b, p. 1).

\section{Research, Education, and Engagement}

The Research, Education, and Engagement Division (REED) provides reference and instructional services to the university and the community. Faculty and Graduate Services (FGS) focuses specifically upon the educational needs of K-State faculty and graduate students, whereas the Undergraduate and Community Services (UCS) department develops instructional content for first-year programs, undergraduate students, and the local community. Although reference is housed in and primarily staffed by the UCS department, employees from multiple departments contribute hours to the Library Help Desk and online reference service. REED librarians consult with Content Development Librarians to assist with resource selection, and to develop collections for curriculum support. University Archives and Special Collections maintain a reading room, and are responsible for collecting university records, manuscripts, and rare books. Special Collections librarians additionally collaborate with Content Development Librarians and preservation staff to evaluate collections, and relocate selected materials to Special Collections (K-State Libraries, 2009b, p. 1).

\section{Administrative and Information Technology Services}

The Administrative and Information Technology (IT) Services Division is responsible for the operational aspects of K-State Libraries. The Human Resources unit assists with hiring, professional development training, payroll, and addressing the concerns of library employees. The Financial Services unit communicates with Content Development and university financial services, to coordinate purchases of library resources, professional development reimbursement, and facilities expenditures. The Building Services unit manages facilities upkeep, event set up, emergency response, and security. Additionally, the IT unit maintains the library's technological infrastructure, integrates library and campus systems, and provides technical support (K-State Libraries, 2009b, p. 2).

The reorganization ultimately transformed the Libraries from a subject-division model into a team-based model. Librarians who had grown accustomed to participating in all three fundamental components of subject specialist librarianship (reference, instruction, collection development), were tasked with reference and instruction, while primary responsibility for collection development was reassigned to Content Development Librarians. In the case of research, education, and engagement, some librarians who were previously assigned by subject specialization joined departments that were defined by user groups rather than academic discipline. Many former librarians chose either Undergraduate and Community Services (UCS) 
or Faculty and Graduate Services (FGS) as their new departmental "home," while others used the reorganization as an opportunity to explore an entirely different aspect of librarianship in one of the new departments or divisions.

\section{Position Restructuring and Role Transformations}

\section{Former Roles of Subject Librarians}

Two of the former subject librarians (and founding members of the Arts Matrix) elected to join Undergraduate and Community Services (UCS) and Faculty and Graduate Services (FGS) and were originally hired to work with academic disciplines in the visual and performing arts. The Visual Arts Librarian was initially liaison to the Department of Art, and the Apparel, Textiles and Interior Design Department, then subsequently, the College of Architecture, Planning, and Design. The Performing Arts Librarian served as liaison for Music, Theatre, Dance, and Communication Studies. The core responsibilities of these two positions were consistent with the traditional subject-collection model, including reference, instruction, collection development, and building relationships with faculty (outreach), thereby establishing a recognized role as a university peer.

Instruction and Reference. Prior to hiring the Visual Arts Librarian and Performing Arts Librarian, there were few formal instruction sessions in place, and limited integration of library and information skills in the curriculum for the disciplines to which they were assigned. As these subject librarians became better acquainted with faculty and the curricula, they collaborated with instructors to plan library visits and instructional sessions for specific classes, and to integrate both information literacy and visual literacy standards into courses. These two subject librarians increasingly worked with their assigned disciplines to investigate and creatively integrate research and information skills, eventually becoming essential parts of the department curricula. Both practiced "embedded librarianship," cultivating a strong presence in courses, and even co-teaching on occasion. The Collections Council necessitated that current and potential uses of library collections motivate purchasing decisions and therefore this close collaboration on instruction additionally benefitted collection development practices. With such intimate knowledge of the curriculum, the subject librarians were able to apply their deep understanding of teaching and research in the disciplines to collection development choices.

Faculty Outreach. For both the Visual Arts Librarian and the Performing Arts Librarian, one of the most crucial elements of faculty outreach was visibility. This obligated librarians to attend department-sponsored events, exhibit openings, and performances, and also seek avenues to increase time spent in departments and meet departmental faculty. By becoming acquainted with faculty and students in more social settings librarians enriched their insights into the research interests of the campus arts community. They additionally benefited from enhanced 
collaboration in graduate and faculty research as both consultants and as co-authors. As the librarians developed a rapport through their involvement in the departments, campus arts, and local arts community, they gradually established reputations as peers in many of the academic departments they liaised with. Faculty engagement coupled with instruction activities also conveyed trust in their knowledge and understanding of the arts disciplines, as well as in their abilities to advocate for the information needs of faculty and students.

Collection Development. Their collection development responsibilities involved accepting requests from faculty, and continually discussing research and teaching requirements to establish collection priorities. This enabled librarians to seek appropriate materials of interest, such as monographs, databases, journal subscriptions, and media, and to construct collection development policies and approval plans. As approval plans often fail to serve as a panacea for collection development, additional work required creating resource lists, and developing strategies to acquire materials. In certain circumstances, this also involved applying for special funds, with which to build the collections in particularly underrepresented areas. Librarians were also able to serve as a resource for faculty in terms of discovering key vendors and publishers. Both librarians were also well connected to a network of art, architecture, music, and theatre librarians through active participation in professional organizations.

\section{Current Roles of UCS and FGS Librarians (2011 - 2013)}

Instruction and Reference. In the new model, the former Visual Arts Librarian chose to work as an Undergraduate and Community Services Librarian (UCS) and the former Performing Arts Librarian chose to work as a Faculty and Graduate Services Librarian (FGS). All UCS and FGS Librarians began with common position descriptions. Eight UCS Librarians and six Undergraduate Specialists provide instruction for undergraduate courses and undergraduate research consultations, as well as partner with campus co-curricular units and departments to liaise with the undergraduate community. Ten FGS librarians are responsible for instruction in graduate courses and consulting on graduate and faculty research. FGS and UCS determined which individual librarians and specialists would work with each of the academic disciplines, and made these assignments in consultation with their departmental library colleagues, primarily based on the academic background, expertise, and interests of each librarian or specialist. Since the reorganization, librarians are no longer encouraged to cultivate "ownership" of a discipline, but are instead expected to work collaboratively with library colleagues in multiple units and departments to develop the best means of meeting the unique needs of each program. Additionally, the UCS Department has responsibility for the Library Help Desk, and library colleagues from a variety of departments help to staff both the in-person and virtual reference services with regular weekly shifts. Reference service is required of UCS Librarians and specialists. 
Within UCS, librarians may elect to focus on either reference or instruction, although everyone contributes to both activities. Undergraduate Specialists were hired to support reference, outreach, and instruction, often teaching first-year information literacy sessions and working with high-enrollment courses. Many smaller teams were formed within the UCS Department as necessitated by collaborative teaching or shared outreach endeavors. Additionally, as the UCS department identified unmet needs, new positions were created to focus on functional specialties rather than academic disciplines. An Undergraduate Experience Librarian, for example, collaborates across campus to tether the Libraries to various campus-wide undergraduate educational initiatives. Additionally, an Instructional Design Librarian and two Instructional Design Residents develop innovative learning objects used in reference and instruction. Similar to UCS, the FGS Department has begun to create functional roles to address specialized services that do not fall within a subject classification, such as a Data Services Librarian position. Librarians in FGS bear more resemblance to subject librarians within their department, but collaborate across departmental lines to contribute to interdisciplinary teams.

Faculty Outreach. Currently, the UCS department has a total of four employees working with the arts disciplines and FGS has four contributing to the arts fields (including architecture and design). Since the two former subject librarians had established relationships with a broad range of academic departments, these two current UCS and FGS Librarians collaborate most closely to strategize and coordinate work across departmental boundaries. To synchronize efforts in teaching and research support for nearly the same arts disciplines that each previously worked on as subject librarians, they both share responsibility for communicating their activities with the Department of Art, College of Architecture, Planning, \& Design, and the School of Music, Theatre and Dance.

Collection Development. In the current organizational structure, the UCS and FGS Librarians continue to collaborate on collection development, but do so from the periphery. With the addition of a Content Development Librarian dedicated to development and management of collections in the Arts, Architecture, and Humanities disciplines, the UCS and the FGS Librarians in the Arts Matrix no longer need to oversee sizeable monograph budgets, and other traditional collection development tasks. Although time spent on the day-to-day activities of collection development is dramatically reduced, both the UCS and FGS Librarian continue to inform and advise these processes as partners with the Content Development Librarian responsible for the Arts and Humanities.

Each of the former subject librarians possesses a depth of knowledge not only of the outstanding needs and wants of K-State patrons, but also of the K-State Libraries collections and how those collections may or may not be relevant to the curriculum and current research undertakings. Additionally, established in professional organizations, they also possess knowledge of best 
practices from the collective wisdom in the arts, having met with key vendors at conferences and subscribed to essential catalogs. The process of sharing this expertise selectively and meaningfully with the Content Development Librarian is ongoing.

\section{Current Role of a Content Development Librarian}

The Content Development Librarian for Arts, Architecture, and the Humanities presented a unique case for the redevelopment of the organizational structure. Being one of the few librarians not employed at K-State Libraries during the prior model, the reorganization did not affect his previous responsibilities and relationships within the university community. This position was an anomaly within the Content Development and Acquisitions Department, where Content Development Librarians for the Sciences and Social Sciences served as subject specialists in their previous traditional roles.

In conjunction with navigating the new organizational structure, the disparity of expertise between the Content Development Librarian and former subject specialists yielded additional challenges. The Content Development Librarian attained a bachelor's degree in Biomedical Science and Middle East History, but possessed limited knowledge of Arts, Architecture, and the Humanities. Rather than assignment of one or two new subjects, the Content Development Librarian was expected to provide specialized collection services for a broad range of departments: Apparel, Textiles, \& Interior Design, Architecture (with a branch library), Art, English, Dance, Modern Languages \& English as a Second Language (ESL), Music, Philosophy, and Theatre. This initial lack of subject expertise served as the root catalyst for the establishment of the Arts Matrix, to balance experience in the matrix, and to reconcile the components of instruction, outreach, and collection development.

The Content Development Librarian's available expertise in Biomedical Science and History, however, afforded excellent preparation for addressing new collection management trends. Much of collection development has shifted toward increased reliance upon analytical data, syncretizing usage statistics (and cost per use) with strategic acquisitions (Morris, 2012, p.12). Given humanities professional's general distaste for metric assessment and number crunching, the Content Development Librarian's skills released the FGS and UCS Librarians from these less gratifying tasks. It has also expanded the Content Development Librarian's role of interaction among librarians and university department faculty, by serving as a consulting liaison for collection management activities, exploring resource needs with greater depth, and developing broad strategies for supporting research and teaching.

Under the reorganization model, aspects of collection development can receive more attention than experienced in the past. What was the part-time responsibility of subject librarians, has 
evolved into the full-time time responsibility of the Content Development Librarian. Although many former subject librarians continue to consider themselves to be spokespersons for the departments to which they were once assigned, Content Development Librarians are the main advocates of resource purchases for the humanities, sciences, and social sciences disciplines. This ensures that budgetary allocations are fairly distributed, and that the Head of Content Development is apprised of specific details, to better justify purchases in a given fiscal year.

In addition to proposing resource purchases, Content Development Librarians provide much of the research, evaluation, and technical work that leads up to purchase proposals. Content Development Librarians review vendor and consortia offerings, selecting only the product trials that strategically enhance library collections. They also configure trials in the electronic resource management system (ERM), and work with UCS and FGS Librarians and university faculty, to complete comprehensive resource evaluations, including annual subscription renewals. This liberates UCS and FGS Librarians to tend to their core responsibilities, and efficiently articulate input at the point it is required. Furthermore, Content Development Librarians maintain all aspects of collections budgets, firm orders, and approval plans. Managing a broader range of subjects attributes a holistic, less partisan approach to materials acquisitions; money can be redistributed according to need within a given fiscal year, without being encumbered by specific subject biases and budget expectations.

With regard to policies, Content Development Librarians collaborate with library administration, crafting statements concerning the acceptance of gifts, collection evaluations, collection development plans, and appropriate workflows for weeding. UCS and FGS Librarians are typically consulted once a policy has been drafted, to share additional concerns as needed. This was a significant change, giving more autonomy to the Content Development Librarian who is charged with managing collections based on metrics, consultations with library faculty, departmental faculty and professional expertise. This arrangement makes it vital that the Content Development Librarian pursue, build relationships with, and communicate well with the above named stakeholders.

Although library instruction is conducted by UCS and FGS Librarians, Content Development librarians frequently partner with UCS and FGS to engage in department outreach. The two UCS and FGS Librarians on the Arts Matrix played pivotal roles in introducing the Humanities Content Development Librarian to key stakeholders in his assigned departments. Each librarian serves as a liaison in some capacity, and can direct the faculty member, graduate student, or undergraduate student to the appropriate librarian for assistance. Patrons are typically referred to Content Development Librarians to answer questions about purchasing materials, setting up product trials, or collection evaluations. Reciprocally, Content Development Librarians encourage faculty members to speak with UCS and FGS Librarians, if it is evident that they require research and instructional services. This illustrates a strength of the Matrix System which 
more efficiently allows the stakeholder to communicate with the person who can most helpfully address their concern.

\section{Matrices}

\section{Matrix Model}

A significant component of the Libraries' reorganization plan was the addition of matrices. A matrix was conceived of as a functional, ad hoc group, for the purpose of addressing interdisciplinary challenges and interdepartmental collaboration. A matrix was viewed as a viable solution to unifying library departments and assembling professional expertise, while maintaining a large degree of autonomy in everyday activities.

The use of matrices is not an exclusive practice of library and information science. The matrix model first developed as the result of labor restructuring in the aerospace industry in the 1960's (Galbraith, 1971). Management sought a more efficient method to improve communication among specialists in isolated roles, and a model that prevented the need to hire additional, intermediary personnel (Galbraith, 1971). The matrix model was viewed as a compromise between functional structures and project organization, to maximize both the use of employee labor and specialized knowledge. Lower level employees were given moderate decision making authority to improve turnaround time, while specialists were only summoned to provide input as needed. It was believed that this measure would prevent jargon dominant meetings, or potential project hijacking by specialists with a narrow comprehension of the project charter (Galbraith, 1971).

The health care and engineering professions have also chosen to adopt matrix models as a productive method of operation. The engineering industry has refined the original structure, adding three gradient models that vary in authority and responsibility (Kuprenas, 2003). In a functional matrix, coordinating authority is given to the project manager, while the department managers still retain control over their staff. In a balanced matrix, project managers and department managers equally share responsibility, making collaborative decisions regarding resource and staff allocation. Lastly, a project matrix places the most authority in the hands of project managers, with the department managers assigning staff members or expertise as needed (Kuprenas, 2003).

\section{K-State Libraries: Matrices}

When the Libraries new organizational chart was mapped, several new relationships were visualized. Commonalities were assessed, and dotted lines were drawn to link divisions that 
could potentially contribute to interdisciplinary functions. Draft departmental descriptions generally embraced the idea of a "matrix" group, but most were unsure of how each division would provide support, and which staff members would be involved. The original vision mimicked the Project Matrix model described by Kuprenas (2003), underpinned by the belief that "matrices should function as high level policy-making groups, while implementation would be accomplished by project teams pulled from across the organization" (K-State Libraries, 2009d).

Initial pairings served as prototype matrices for the reorganization, and emerged out of themes consisting of collections, services, and digital initiatives. In theory, matrices were meant to evolve organically as the reorganization progressed based on the needs identified by staff; therefore, these examples illustrated the philosophical framework and potential for matrices to facilitate communication and collaboration. Due to the inherent fluidity of the matrix model, from 2009-2010, library staff expressed confusion about these partnerships, and requested clarification about the internal composition of a matrix. The purpose of each matrix was generally unclear to library staff, and there was little indication as to how many staff members should serve on a matrix, and who would be asked to participate (K-State Libraries, 2010b). It was also undecided if authority could be given to make decisions, or if a member could serve as a proxy for the Dean, Associate Dean, or Assistant Deans (K-State Libraries, 2009e).

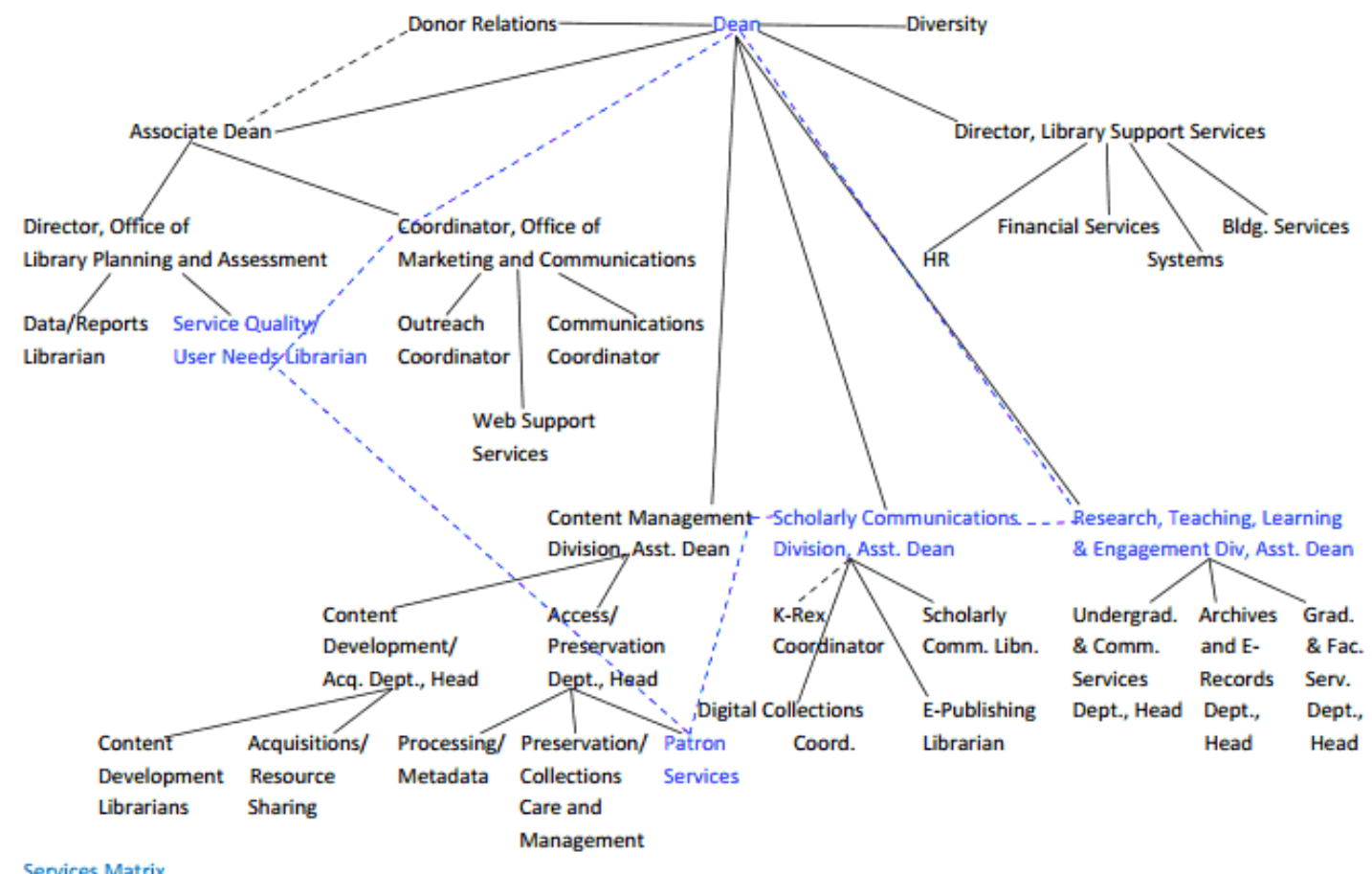

Fig. 4 Sample matrix handout, "Service Matrix," (K-State Libraries, 2009a). 


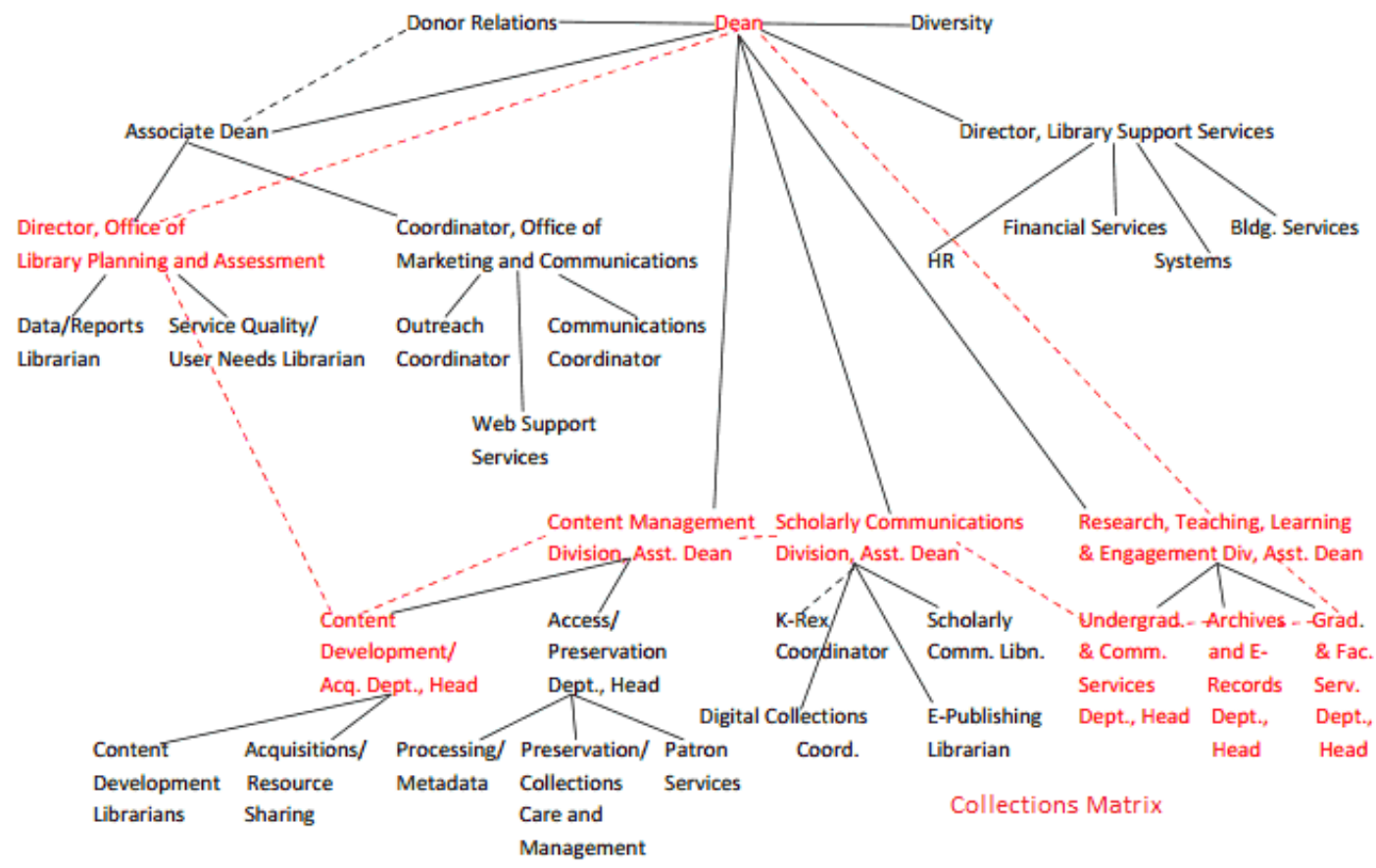

Fig. 5 Sample matrix handout, "Collections Matrix," (K-State Libraries, 2009a).

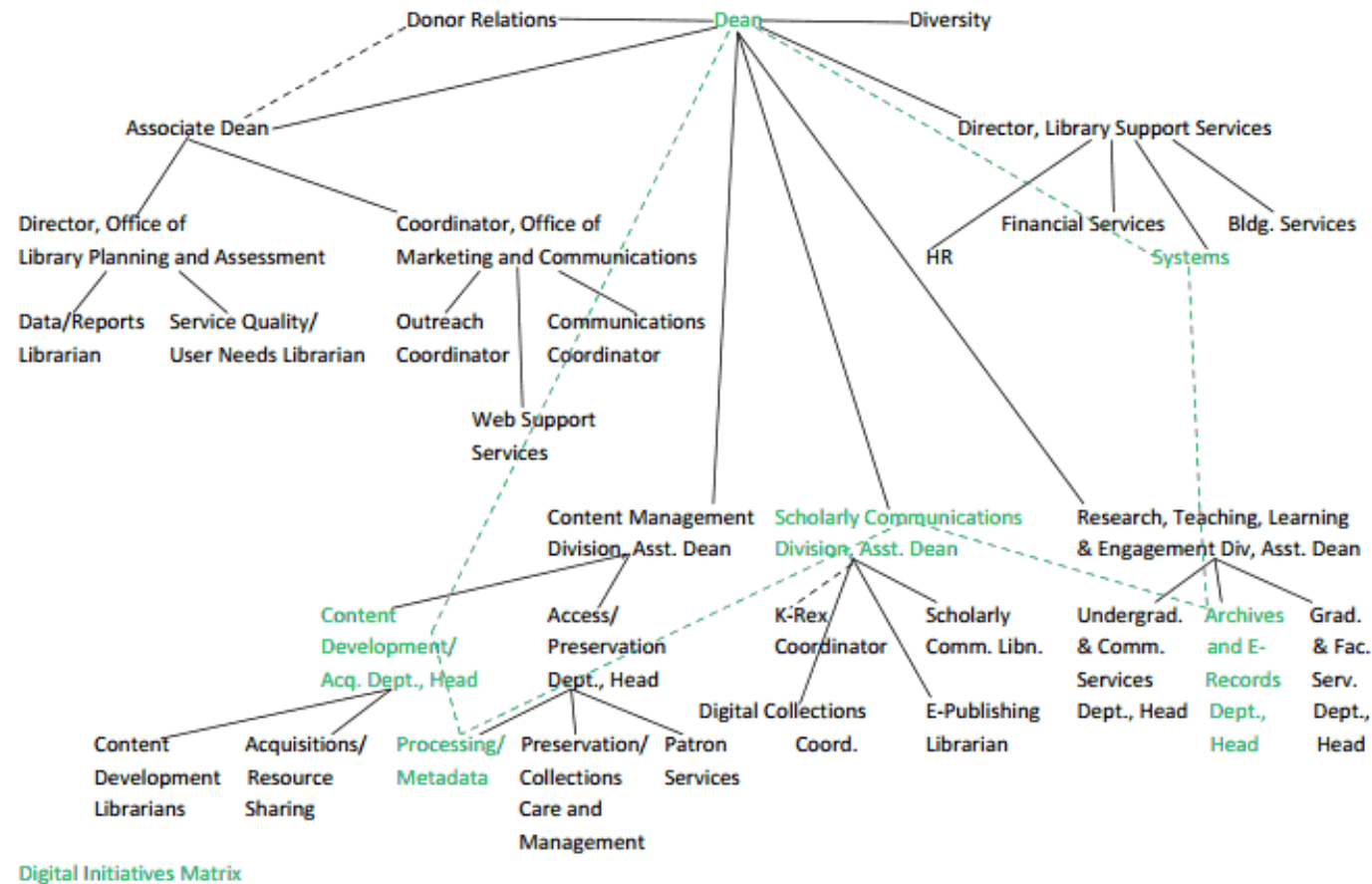

Fig. 6 Sample matrix handout, "Digital Initiatives Matrix,” (K-State Libraries, 2009a). 
As new projects emerged, it was deemed necessary to reevaluate the purpose of the matrix model. The Services, Collections, and Digital Initiatives matrices were too large to be effective, and it became apparent that more granular matrices were needed. Rather than forming matrices at the department head level, librarians and staff asked permission to create their own matrices, addressing library functions and curriculum based support initiatives. The Collections and Services matrices gradually dissolved, with functions being served in subject matrices. In the case of the Digital Initiatives matrix, it was split into two more manageable groups.

During the next phase, smaller matrices began to cultivate informally throughout the Libraries, yet general confusion persisted as there was no clear definition as to how the matrices would function, or what the formal structure would resemble. Staff meetings were convened to discuss these issues, but they were unable to determine if matrices should operate at the subject level, or if they could be developed to support popular classes at the university (K-State Libraries, 2010b). Several departments, such as Content Development, listed how matrices would be beneficial to link other units, but did not indicate that any members presently belonged to confirmed matrices. It was also asked if matrices could enact decisions, thus demonstrating a hesitancy to form matrices if authority were severely restricted (K-State Libraries, 2011b).

Without any formal procedures in place, several matrix groups emerged, but often existed without the knowledge of other library members. This inevitably led to multiple groups addressing similar concepts, independently of one another. The Faculty Recruitment matrix (KState Libraries, 2008a) wavered between a standing body of regular members, and individual search committees that were formed to hire specific positions. The Libraries IT Committee labeled themselves as an unofficial (and therefore unidentified) matrix, citing that their duties fell within the definition implied by library administration, "pulling individuals from across the organization together to work on a common goal" (K-State Libraries, 2009c). Additionally, subject matrices had been designed in several areas, but it was difficult to discern what groups currently existed, and what services should be managed, such as replacing the Collections Council that formally advised resource purchases (K-State Libraries, 2011a).

On October 24, 2011, the Libraries' Office of Planning and Assessment (LPA) released a survey for the purpose of analyzing the effectiveness of the reorganization. Out of the 109 total faculty and staff members at K-State Libraries, 41 employees responded (38\%), offering feedback about the positive and negative aspects of changing jobs and responsibilities. Overall, 81 percent viewed the reorganization as somewhat successful to very successful. Nineteen percent believed the transition was unsuccessful, and that further work was needed to rectify problematic conditions (K-State Libraries, 2011c). Among the dissenting opinions, employees expressed the need for more staffing and better communication. There were several comments regarding matrices, with some asking if matrices would be used or not, or if they were creating matrices correctly, requesting more formalized parameters. 


\section{TAKE IN FIGURE 7}

From the feedback received, it was determined that the Office of Planning and Assessment (LPA) would spearhead documentation for matrix groups (K-State Libraries, 2011b). The Head of LPA sent out a Libraries-wide call, requesting that matrix-like assemblies identify themselves for evaluation. The Head of LPA visited each group as they met over July and August of 2012. Matrix members were asked to provide the following information:

1.) An official title for the matrix

2.) Matrix members

3.) Purpose of the matrix

4.) Missions or goals

5.) Specific projects to be completed or outcomes achieved

6.) Meeting frequency

7.) Minutes from a past meeting

Subsequently, most of the matrix groups were approved or conditionally approved by the K-State Libraries Office of Planning and Assessment, with the understanding that revisions would be made to clarify goals, meeting frequency, or participating members. Nine matrix groups were formally confirmed, and currently operate at K-State Libraries (as of mid-2013):

1. AgBioSci

2. Digital Preservation

3. Digital Projects

4. Education

5. Government Documents

6. Humanities

7. Social Sciences

8. Sustainability

9. Arts (Art; Music; Theatre/Dance) 


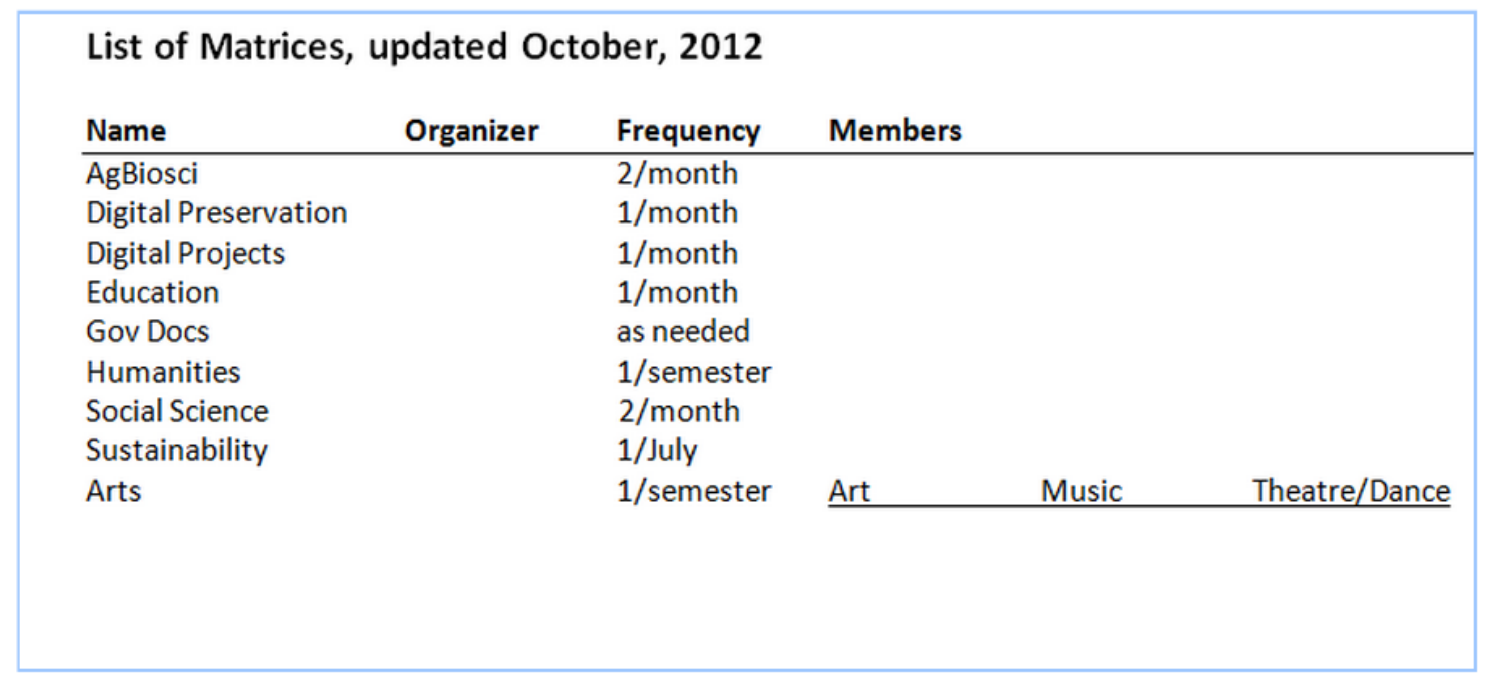

Fig. 7 K-State Libraries List of Matrices (K-State Libraries Office of Planning and Assessment, 2012)

At the end of the evaluation cycle, the Libraries' Office of Planning and Assessment asked that all library staff coordinate future matrix development through their department. Additionally, LPA offered to provide continued guidance to current matrices, if it was felt the mediation was needed to improve efficiency.

Although many matrix groups are similar in structure, most function differently to achieve distinctive goals. For purposes of this case study, the Arts Matrix illustrates how a matrix has replaced the traditional subject division model. In the next portion of the paper, the interworking of the matrix will be analyzed in further detail, including an assessment of the advantages and disadvantages of working in this particular organizational model.

\section{K-State Libraries: Arts Matrix}

A review of the literature uncovered an existing gap in the study of matrix groups and libraries. Whereas several studies have analyzed the use of matrices in the aerospace, engineering, and nursing occupations, no research has explicitly covered library 'matrices.' Rather the profession seems to use the term 'team-based organization' which as an overarching designation is opaque, and defines a variety of models. Therefore, K-State Libraries offers herein a unique glimpse of the Arts Matrix and its constituents within a holistic frame, including an assessment the matrix model itself and its ability to provide essential library services.

The Arts Matrix was catalyzed by a personnel change and the hiring of a new librarian to fill the Content Development Librarian position for Arts, Architecture, and the Humanities in September 2011. Since the new hire was not familiar with K-State's current department faculty and research priorities, formation of a matrix group was regarded as an opportunity for former 
subject specialists to transfer their expertise to the new librarian, as well as avenue for the Content Development Librarian to disseminate knowledge or solicit feedback on resource purchases.

The beginning stages of matrix development were completed electronically, with potential members communicating by email. The tenured and most senior member of the forthcoming Arts Matrix surveyed all library members, gauging interest in a matrix to brainstorm collaborative services in the Arts disciplines. Those who wished to participate met in April 2012, to begin conceptualizing what would become the Arts Matrix.

The initial stakeholders in the Arts Matrix were the UCS Librarian for the Arts and Architecture, the FGS Librarian for the Arts and Architecture, and the new Content Development Librarian for Arts, Architecture, and the Humanities. Additional employees in UCS, FGS, and Scholarly Communications were asked to join, as well as UCS Specialists who assist with instruction and reference in the Arts disciplines, all in consultation with their supervisors. At present the matrix has 8 members, with select members granted consulting membership, allowing for meeting attendance only when their area of expertise was needed or a particular agenda item was of interest. This arrangement sought to improve job efficiency, and maximize members' abilities to concentrate on essential responsibilities.

The first two meetings in April and August of 2012 were utilized to compose a statement of goals. Members unanimously agreed on an informal structure, which offered enough flexibility to resolve immediate and long standing matters. An online document was shared among all group members, providing collaborative access to meeting notes, and future meeting agendas. Although malleability was a crucial characteristic of the matrix, it was generally recognized that some themes should be instituted, to impose some guidance and progression toward outcomes. At this point, the matrices are autonomous in order to allow them to address the unique needs of their stakeholders. A discussion elicited the following categories to serve as a regular meeting agenda structure for the Arts Matrix: announcements, discussion/feedback, projects, professional development, and socializing. Some examples of how each of these is currently used by the Arts matrix follow below.

Announcements. Announcements serve as a forum for individuals to share current activities and solicit project collaborators. Librarians may inform members about information literacy sessions taught, research consultations performed, or embedded roles in specific courses. Announcements are also an opportunity for librarians share information from academic departments, such as service expectations articulated by academic teaching faculty or information about new faculty hires, visiting scholars, or graduate teaching assistants. Group members might also share information regarding distinguished lecturers or events on campus and new classes or departments approved by the university, to ensure that support is allocated for 
those areas. The Content Development Librarian might highlight new resources purchased such as databases, e-book packages, and streaming media products; and make announcements to inform all matrix members, thus eliminating the need to schedule meetings individually.

Solutions. Announcements provide a useful forum for exposing and addressing current problems or lack of support. When issues are objectively reported and documented the group can act as a source of support and help develop solutions. Scope creep was curtailed through such discussions, as all members brainstorm to solve identified problems. Solutions may take a variety of forms, from simple clarifications of announcements, to chronic issues requiring significant planning and multiple contributors. The Arts Matrix provides a forum for issues to be expounded, so the appropriate individuals can take responsibility, while also arriving at a solution through consultation with the group. Rather than one subject librarian having to bear the brunt, the Arts Matrix divides labor among its members.

Projects/Collaborations. Projects serve as the fundamental basis of the matrix, not only to produce measurable outcomes, but also identify practices for engaging academic department faculty members. In the course of the reorganization, matrix projects were used to target underserved departments, and to validate the Libraries' commitment to providing relevant services. For example, the Dance Department at K-State had historically been oriented toward applied performance, rather than library research. The Arts Matrix group provided a channel for discussion of a streaming dance video collection, as well as development of a pilot proposal to reformat essential dance media. This project improved relations between the Libraries and the Dance Department, and increased interaction between matrix members and the Dance faculty.

The original Arts Matrix charter listed several projects to explore, but members are free to propose new projects as need demands. Projects are submitted and voted on, and approved projects are assigned to matrix members for follow-up according to their expertise or authority. This serves as a more efficient model, requiring that only specific matrix members attend a meeting or a portion of a meeting. Shared documents enable matrix members to determine in advance when to attend meetings and in what capacity. They also enable members to read notes at their convenience, and yet still remain informed participants.

Professional Development. As the duties of the Arts Matrix expanded, the need for professional development and skills workshops was expressed, since taking on new subject areas produced anxiety for some members less familiar with those disciplines. Arts Matrix members agreed that cross training would be helpful, to improve knowledge and comfort for collaborating within the Libraries and with academic departments. Consequently, the Arts Matrix also searched for opportunities which coupled group mentoring and conferences. To achieve this, subject specialists were paired with less experienced librarians and matrix members to empower networking opportunities, and expose them to new organizations promoting the latest research. 
In recent years, members of the Arts Matrix have attended the Art Libraries Society of North America's Central Plains Chapter meetings. This organization has imparted a wealth of new contacts and information, and provided opportunities for group scholarship and presentations.

Additionally, matrix members regularly attend community events, such as art shows, theatrical performances, and public lectures. This proved beneficial in several ways. It demonstrated the Libraries' support of academic department faculty and community stakeholders, which has proved invaluable in establishing contact points and building friendships. Lastly, it has helped librarians to exit the library, and gain a better perspective of the community at large. These events allow us to step out beyond the K-State sphere, and see community functions outside of university life.

Social. The social elements of matrices vary from group to group, depending upon the commitment and personalities of the members. Arts Matrix members formed highly congenial relationships, which enabled the group to complement each other's strengths and weaknesses. Having lunch or going for a walk allowed for connections that help to delegate work in ways which did not overwhelm members. This added benefit helps to create a better work-life balance to maximize productivity and minimize burnout.

\section{Conclusion}

\section{Matrix Model: Benefits}

Flexibility is one of the greatest strengths of this unique, team-based model. The Libraries are better able to respond to change and adapt to unanticipated circumstances. Additionally, employees are positioned to take advantage of opportunities that perhaps an over-committed subject librarian would not have the time or desire to pursue. In the past, when the potential for a new project or collaboration emerged, completion could heavily depend upon time constraints or career priorities of the individual. Today, employees are empowered to collaborate, and harness expertise from across the organization, thereby maximizing the Libraries' ability to fulfill organizational and university goals. Prior to the reorganization, many employees with professional experience and/or academic training in particular fields of study were either underutilized or overlooked in a structure that deferred to siloed subject specialists. Through collaboration and shared responsibilities, the Libraries maximize the application of talents and expertise and deploy personnel to the greatest advantage of library employees and patrons. The flexibility of this model also enables greater coverage of topics, compensating for any weaknesses in the collective expertise. Additionally, by cross-training, more personnel are ready to respond to patron needs when "the" expert is out of the office. This also positively impacted time management for individual employees who were no longer bound to participate in activities by virtue of their subject assignment, but instead can respond as requested by the matrices. 
The new organization also enables a novel philosophical approach to instruction. Within this fluid structure, both individuals and groups are better able to experiment; some examples include: addressing interdisciplinary concepts such as sustainability, developing expertise in particular categories of information such as Government Documents, pursuing originality in teaching and learning such as the "gamification" of instruction, or enhancing their pedagogy through student-centered learning or implementing the flipped classroom model. By dividing duties across introductory, advanced undergraduate and graduate level courses, and re-assigning development and management of the collection to Content Development Librarians, UCS and FGS Librarians inherited time to collaborate with faculty more innovatively. Pursuits such as embedded librarianship were much more difficult to undertake in the subject librarian model if for no other reason than the time commitment required. Librarians also increasingly engage in service learning, developing programming, leading training, and creating more opportunities to deepen their understanding of the nature of teaching and research at K-State. By devoting more time to building relationships with members of the K-State community, librarians are engaged in actively promoting the work of the organization to the campus and continue to earn the trust and respect of both students and faculty.

With regard to content development, there are no longer single gatekeepers for each discipline. Content Development Librarians are able to give more of their time and consideration to development and management of collections than subject librarians could in the previous organization. In the new model, all academic disciplines receive equal attention. Rather than filtering requests from fields with a wide variety of needs and priorities through a single queue, Content Development Librarians work collaboratively to address collections holistically and much more strategically. It is also easier for Content Development Librarians to actively pursue collaboration and engage in collection analysis. The processes of fulfilling requests and responding to collections-related questions are more efficient and expedient, and competition for resources has abated.

\section{Matrix Model: Challenges}

While the library reorganization and matrix model have been successful in several areas, it has not been a panacea for all obstacles in the workplace. The issue of time has been addressed across the organization as employees adjust to a high volume of changes, create new roles, and develop collaborative ways of working. Overall, time management has been a primary consideration for many units and departments in the Libraries following the reorganization. Another universal challenge is the notion of identity. Whether roles changed, responsibilities were added, duties were surrendered to colleagues, reporting lines changed, or new employees were hired, all employees experienced some measurable difference in the new organization. 
As an example of the challenge presented by identity, in the subject librarian model librarians were encouraged to self-promote and cultivate an identity as the sole liaison between particular academic departments and the Libraries. This relationship was clear from the perspective of both librarians and most faculty members, who understood that one librarian was assigned to their department. Following the reorganization, many faculty expressed confusion over how to navigate the team-based model, unclear about whom to approach for assistance with specific services or requests. Librarians also expressed confusion regarding their new roles. They occasionally reverted to old relationships out of familiarity or efficiency, finding completing certain tasks easier than training a colleague. In other instances, librarians may have preferred to work alone or felt apprehensive of the new model when asked to take on new subjects. These new, unfamiliar subjects may have been assigned to areas they possessed limited knowledge of, or simply disliked. Many librarians were unaccustomed to addressing the unknown, having worked to cultivate expertise over their careers. Attempts to build teams therefore met with mixed results as certain matrix groups failed or have stagnated.

Content development presented unique challenges, again, experienced from within and outside the Libraries. In some cases, content development has become disconnected from subject expertise, a challenge that the matrix model is meant to address. Developing new ways of working and establishing effective and efficient modes of communication, however, must evolve over time and with participation from all matrix members. Furthermore, departmental faculty accustomed to consulting with former subject librarians on collection development, may be unwilling to cultivate a relationship with a new librarian having established a rapport with their previously assigned liaison. In addition, Content Development Librarians are perhaps responsible for too many subjects, and the inability of approval plans to sufficiently replace firm orders limits the amount of attention that can be applied to individual subjects.

Lastly, the Library reorganization survey indicated dissatisfaction with communication throughout the organization. Respondents reported a desire for improved channels of communication both across library departments and between the Libraries administration and individual units. Clarification was requested to perform jobs more competently, specifically subject knowledge linking the Undergraduate and Community Services, Faculty and Graduate Services, and the Content Development \& Acquisitions Departments.

\section{Future Considerations}

Perceiving challenges as inherently negative inhibits the ability to overcome whatever one wishes to address. However, if one considers the opportunities presented within a challenge the power shifts to the hands of the opportunist. This philosophical framework underpins the work of the Arts Matrix. The former subject librarian members of this matrix continually seek to impart their subject expertise and departmental insight to members of the matrix in a meaningful, 
timely fashion, as well as open their minds to the fresh ideas and insights of their colleagues. This established the group as a forum for developing a shared, base understanding of materials, instruction activities, faculty collaborations and bonding library operations across departmental lines. As time passes, members of the Arts Matrix are better able to express their own needs and wishes regarding how the matrix can facilitate their work. Moving forward, it is increasingly important to delineate a fluid process of open communication that moves beyond the matrix and into job responsibilities. It is with this understanding in mind that the matrix will continue to reinvigorate communication with academic departments and unify the functional roles of librarians to more effectively communicate with patrons.

It is also essential to provide faculty with direct access to specific librarians, and help matrix members understand patrons with more depth. More time spent outside of the library enables and empowers interactions with students and faculty. All members of the Arts Matrix should function as advocates for the visual and performing arts from sincere insight into who our patrons are, what motivates them, what constitutes research in the arts, and how traditional resources inform the work of students and faculty. Members of the matrix intend to increase involvement in academic departments to cultivate personal knowledge of the curricula and research needs. The Arts Matrix can also facilitate event attendance and cross-training to promote connections with these disciplines, thereby additionally bonding the team through shared experiences. Although adjustment to the reorganization will take time and further refinement, members of the matrix will devote themselves to involvement in academic departments, while promoting connections beyond library materials and transcending theory. This flexibility will continue to allow K-State Libraries to develop and provide relevant resources and services to patrons for years to come.

\section{Appendix A: K-State Libraries’ Reorganization Satisfaction Survey}


The Office of Library Planning and Assessment is soliciting your feedback regarding our recent reorganization. Periodic assessment of the reorganization is important to assuring that we are on track or need to make adjustments. The first step is to gather information from staff. Please share with us your ideas and comments about the reorganization, focusing on library processes rather than behaviors or specific people. These comments will be shared as written with the Strategic Leadership Council and the summary results will be shared with library staff. Names will be removed and other identifiers will be removed to the best of our ability.

1. Up to this point, please rate the overall success of the re-organization on the following scale:

Not successful 1 somewhat successful 2 3
Very successful

45

2. What positive changes do you see as a result of the reorganization? What is working well?

3 . Are there any gaps in the work or service we are doing?

4. Are there barriers to getting your work done? If so what are they?

5. Are there things we can stop doing or do differently?

6. Do you have any additional comments about the reorganization? 
Management of Content and Engagement through an Arts Matrix

\section{References}

Andrade, R., Zaghloul R. (2010). Restructuring liaison librarian teams at the University of

Arizona. Libraries, 2007-2009. New Library World, 111(7/8), 273-286. doi: $10.1108 / 03074801011059911$

Carnegie Foundation for the Advancement of Teaching. (2010). Institution profile: Kansas State University. Retrieved from http://classifications.carnegiefoundation.org/lookup listings/view_institution.php?unit_id=155399\&start_page=index.php\&clq=\%7B\%22basi c2005_ids\%22\%3A\%2216\%22\%7D

Feetham, M. (2006). The subject specialist in higher education: A review of the literature. In P. Dale, M. Holland, \& M. Matthews (Eds.). Subject librarians: Engaging with the learning and teaching environment, (pp. 3-18). Alsdershot, UK: Ashgate.

Galbraith J. R. (1971). Matrix organization designs: How to combine functional and project forms. Business Horizons, 14(1), 29-40.

Kansas State University, News Services. (2010). K-State Libraries Names New Assistant Deans, Department Heads. Retrieved from http://www.kstate.edu/media/ newsreleases/jul10/ library71410.html

Kansas State University, Office of the President. (2013b). K-State 2025: A visionary plan for Kansas State University. Retrieved from http://www.k-state.edu/2025/plan/goals.html

Kansas State University, Research and Extension. (2013c). Map for K-State Research and Extension. Retrieved from http://www.ksre.ksu.edu/map.aspx

Kent, A., Lancour, H., \& Daily, J. (1978). Reference services and libraries. In the Encyclopedia of Library and Information Science. (Vol. 25, pp. 212-215). New York: Marcel Dekker.

K-State Libraries. (2006). A living strategic plan: K-State Libraries, 2007-2012. Manhattan, KS.

K-State Libraries. (2008a). Round robin: LLC meeting notes, 7-29-08. Retrieved from http://ksulib.typepad.com/bulletin/2008/08/round-robin.html

K-State Libraries. (2008b). Organization chart. Retrieved from http://web.archive.org /web/20080829152141/http://www.lib.k-state.edu/geninfo/docs/orgchart.pdf 
Management of Content and Engagement through an Arts Matrix

K-State Libraries (2009a). K-State Libraries reorganization plan, May 2009. Manhattan, KS.

K-State Libraries (2009b). K-State Libraries: Snapshot of the new organization, revised 07/08/09. Manhattan, KS.

K-State Libraries (2009c). LIT minutes 28 May 2009. Retrieved from http://ksulib.typepad. com/bulletin/2009/06/lit-minutes-28-may-2009.html

K-State Libraries (2009d). LLC Meeting: 06/30/09. Retrieved from http://ksulib. typepad.com/bulletin/2009/07/1lc-63009.html

K-State Libraries (2009e). LLC Meeting: 11/24/09. Retrieved from http://ksulib.typepad.com/bulletin/2009/11/llc-meeting-notes-112409.html

K-State Libraries. (2010a). K-State Libraries organizational chart. Retrieved from http://web.archive org/web/20100610114852/http://www.lib.k-state.edu/comm/orgchart.pdf

K-State Libraries. (2010b). Reference meeting October 18, 2010. Retrieved from http://ksulib.typepad.com/bulletin/2010/10/reference-meeting-october-18-2010.html

K-State Libraries. (2011a). Meeting notes from faculty and graduate services department 3-10-2011. Retrieved from http://ksulib.typepad.com/bulletin/2011/04/meeting-notes -from-faculty-and-graduate-services-department-3-10-2011.html

K-State Libraries. (2011b). UCS/FGS joint meeting notes-April 22, 2011. Retrieved from http://ksulib.typepad.com/bulletin/2011/05/ucsfgs-joint-meeting-notes-april-222011.html

K-State Libraries, Office of Planning and Assessment. (2011c). Reorganization staff survey, November 16, 2011. Manhattan, KS.

K-State Libraries, Office of Planning and Assessment. (2012). List of matrices, updated October, 2012. Manhattan, KS.

Kuprenas, J. A. (2003). Implementation and performance of a matrix organization structure. International Journal of Project Management, 21(1), 51-62. 
Management of Content and Engagement through an Arts Matrix

Morris, R. (2012). What's the use? Perspectives on usage statistics across the information industry. Against the Grain, 24(4), 1-12.

New Prairie Press. (2013). About US. Retrieved from http://newprairiepress.org/home/about.php

University of Guelph Library. (2013). Team based service model. Retrieved from http://www.lib.uoguelph.ca/about/team_based_service_model.cfm 
Management of Content and Engagement through an Arts Matrix 